\title{
Evaluation of Flight Parameters During Approach and Landing Phases by Applying Principal Component Analysis
}

\author{
Sameer K. Jasra ${ }^{1}$, Gianluca Valentino ${ }^{2}$ \\ University of Malta, Msida, MSD2080, Malta \\ Alan Muscat ${ }^{3}$ \\ QuAero Ltd., Mosta, MST3503, Malta \\ David Zammit-Mangion ${ }^{4}$ and Robert Camilleri ${ }^{5}$
University of Malta, Msida, MSD2080, Malta

\begin{abstract}
This paper adopts an unsupervised learning technique, Principal Component Analysis (PCA) to analyze flight data. While the flight parameters for a stable approach have been established for a while, the paper reevaluates these flight parameters using PCA for a set of airports across the United States of America. Some flight parameters were found to be more sensitive to some airports. The parameters have been cross-checked with experts in the industry to better interpret their significance.
\end{abstract}

\section{Nomenclature}

$M=$ PCA matrix

$M=$ total number of flights in the matrix $\mathrm{M}$

$N=$ total number of dimensions (feature space)

$P=$ total flight parameters for a given flight

$D=$ total time-steps recording flight parameters

$V i=$ total variance explained by the principal components

$F=$ total number of principal components generated

$Z=$ total number of principal components kept

$X=$ total number of anomalous flights for a given airport

$p_{i d_{j}}=\quad$ value of the $i^{\text {th }}$ parameter from ' $p$ ' total parameters recorded at $j^{\text {th }}$ time-step

\section{Introduction}

Flight data recording is mandatory in civil aircrafts in many countries across the world. Flight Operational Quality Assurance (FOQA) is an activity carried out by the airlines primarily as a means of monitoring and improving the safety and operation of their aircraft [1]. The importance of FOQA activity has been highlighted by several aircraft accident investigation reports [2]. The flight data analysis currently adopts a system of threshold exceedance detection, whereby certain flight parameters (typically referred to as maxvals) are flagged whenever they exceed the threshold limit. However, anomalous values below the threshold can still be a potential risk. Analysis of such parameters makes FOQA laborious and time consuming. With the recent developments in big data, massive amounts of high-dimensional or unstructured data can be analysed using modern techniques. There is an ever increasing need to adopt such modern

\footnotetext{
${ }^{1}$ Ph.D. student, Institute of Aerospace Technologies, and AIAA Student Member.

${ }^{2}$ Lecturer, Department of Communications and Computer Engineering.

${ }^{3}$ Director, QuAero Limited.

${ }^{4}$ Director, Institute of Aerospace Technologies, and AIAA Senior Member.

${ }^{5}$ Lecturer, Institute of Aerospace Technologies.
} 
techniques to analyse flight data, and therefore extracting more valuable information from it. This paper adopts such a technique to re-evaluate important flight parameters during approach and landing phases.

\section{Approach and Landing Phases}

The paper uses the approach and landing phases as a case study. From the statistics presented in Fig. 1, it can be seen that Approach and Landing Accidents (ALAs) account for more than 50\% of all the accidents though it's just 16\% of the flight time $[3,4]$. Conducting a safe and efficient landing is of key importance to all the stakeholders involved. Multiple objectives like minimizing fuel burn, maintaining low noise, reducing operating costs and primarily maximizing safety are the factors determining the landing profile for an aircraft. The approach phase of the flight begins when the pilot initiates changes in the aircraft configuration and/or speeds enabling the aircraft to manoeuvre for the purpose of landing on a particular runway. A stabilised approach is one during which several key flight parameters are controlled to within a specified range of values before the aircraft reaches a predefined point in space relative to the landing threshold (stabilization altitude or height) and maintained within that range of values until touchdown. The parameters include attitude, flight path trajectory, airspeed, rate of descent, engine thrust and correct aircraft configuration. [5]
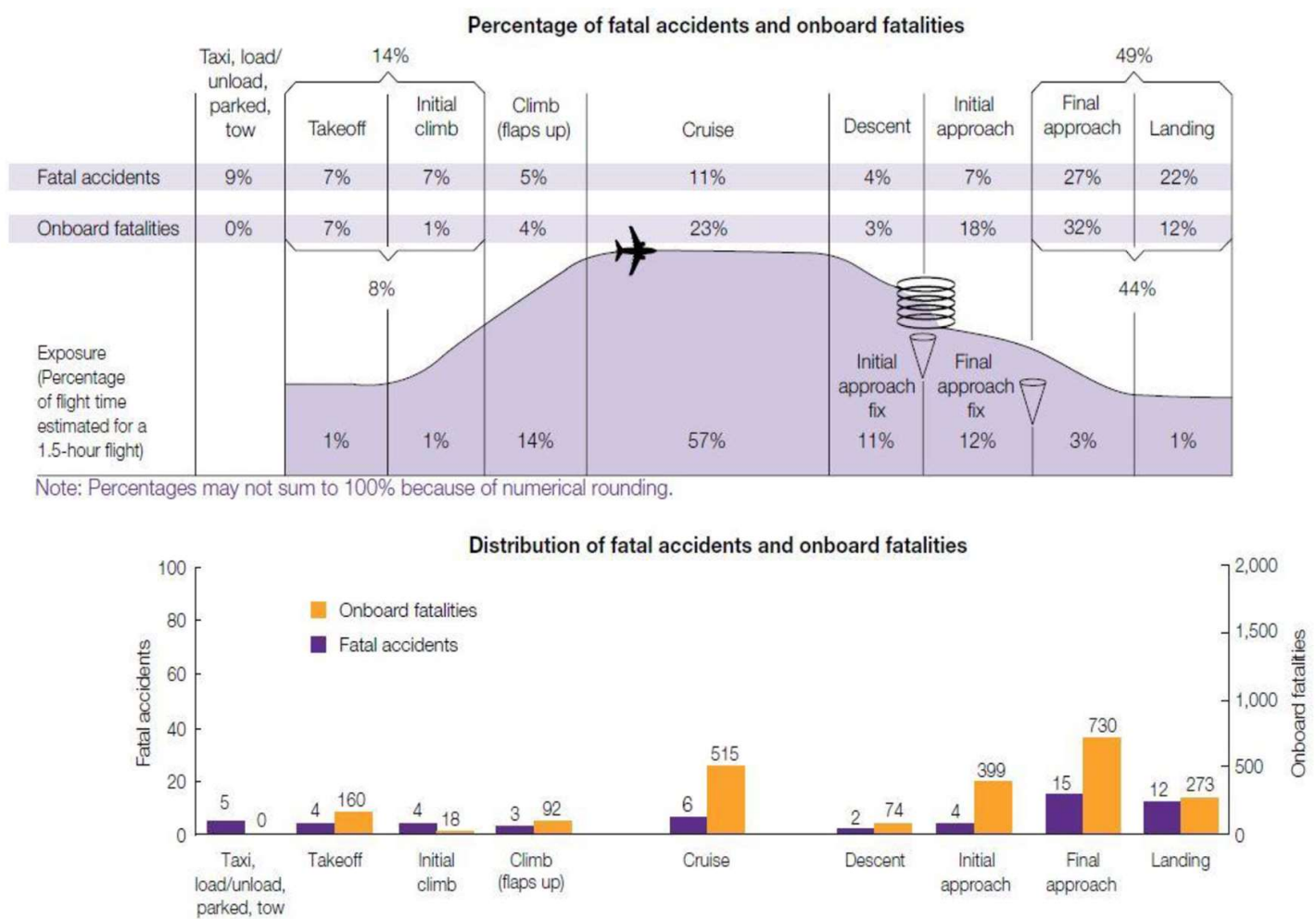

Fig. 1 Fatal accidents and onboard fatalities by phase of fight (2008-2017)

From years of experience, the aviation community has recognized that establishing and maintaining a stabilized approach is a major factor helping in safe landings [5]. A safe landing and completion of the landing roll within the available runway is the culmination of a complex process of energy management that starts at the top of descent, from which point the sum of kinetic energy(speed) and potential energy (altitude) must be appropriately dissipated to achieve taxi speed before the runway ends. A common set of parameters that constitute a stabilized approach have been defined in [5] as follows:

- Target approach speed a few knots faster than the desired touchdown speed and on the 'right' side of the total drag curve (corrected for wind if necessary);

- Rate of descent commensurate with the approach angle and approach speed (generally Inertial Vertical Velocity (IVV) around 600-700 feet per minute for jet aircraft on a $3^{\circ}$ approach);

- Proper landing configuration (landing gear and flaps extended) below a set threshold altitude (usually 1,000 feet for instrumented flight rule (IFR) approaches and 500 feet for visual flight rules (VFR));

- Stable aircraft attitude in all 3 axes;

- Engine thrust (Engine 1 N1 Speed) stable above idle. 
With the introduction of more powerful data analysis techniques, this paper re-evaluates the criteria for a stable approach. The paper therefore attempts to answer the following research question: Are the parameters used for the stabilisation criteria backed by flight data records? Can these set of criteria be generalised over a range of aircraft types, and airports? The paper analyses flight data from open-source records, freely provided by NASA (National Aeronautics and Space Administration). The files contain actual data recorded onboard a single type of regional jet operating in commercial service over a period of four years. This paper derives results from three tail numbers with a total of 3000 flights to five separate airports in the USA. The airports are listed in Table 1. The following section explains the preprocessing and principle component analysis technique used to derive the results demonstrated.

Table 1 List of airports analyzed

\begin{tabular}{|l|l|}
\hline Airport IATA Code & Airport Description \\
\hline CVG & Cincinnati/Northern Kentucky International Airport (Kentucky) \\
\hline DTW & Detroit Metropolitan Wayne County Airport (Michigan) \\
\hline MEM & Memphis International Airport (Tennessee) \\
\hline MSP & Minneapolis-Saint Paul International Airport (Minnesota) \\
\hline OKC & Will Rogers World Airport (Oklahoma) \\
\hline
\end{tabular}

\section{Flight Data as Big Data}

With the recent developments in big data, massive amounts of high-dimensional or unstructured data can be analysed using modern techniques. There is an ever increasing need to adopt such modern techniques to analyse flight data, and therefore extracting more valuable information from it. However, this brings computational challenges. The major challenge in analysing flight data is that it has inherent problems of big data like heterogeneity, scalability, noise accumulation, spurious correlations, incidental endogeneity to name a few [6]. Traditional computational techniques employed in big data analysis that perform well for moderate sample size may not scale to massive data size of flight data. For example, the Digital Flight Data Recorder on Boeing 787 can record approximately 2000 parameters for 50 hours, compared to the minimum requirements of 88 flight parameters for 25 hours [7]. Modern machine learning algorithms may therefore have an important role to play in analysing flight data more efficiently and making suitable to make future predictions from existing flight data [8,9]. A literature review of such techniques has been presented in [10]. This paper focuses on the use of Principal Component Analysis (PCA). Generally, PCA is used as a pre-processing technique, establishing which of the parameters are more significant for the particular problem being studied, reducing the dimensionality of the data and thus making further analysis less computationally intensive.

Reducing the dimensions of time series data as in the case of flight data is very important not only to save computational time and space but also to better visualize the data, implement machine learning models and most importantly reduce the curse of dimensionality [11], a common problem in the era of Big Data. In this paper PCA is not only used as a dimensionality reduction technique for time series data but is also used to establish the important parameters during approach and landing phases, backed by the data.

\section{Principal Component Analysis}

Principle Component Analysis (PCA) is a technique traditionally used for dimensionality reduction, thus helping to reduce the number of features or variables in data set under consideration. In flight data, the goal is to reduce the number of flight parameters, and at the same time, retain as much of their class discriminatory information as possible. Dimensionality reduction can generally be achieved by two methods, feature selection and feature extraction. Feature selection is the procedure in which, given a number of features, one selects the most important of them [12]. On the other hand, feature extraction creates new features based on transformations or combinations of the original feature set [13]. The benefit of feature extraction over feature selection is that this procedure can reduce not only the cost of recognition by reducing the number of features that needs to be collected, but in some cases, it can also provide a better classification accuracy due to finite sample size effects [13]. This paper applies PCA as a feature extraction technique to analyze flight data as the new components generated will encapsulate the original flight parameters.

PCA is a technique used to examine the interrelations among a set of features in the data set in order to identify the underlying structure of those features. It transforms data into an orthogonal coordinate system based on the variance in the data [14-16]. The greatest variance by any projection of the data is mapped on the first principal component, the second greatest variance on the second, and so on. This paper attempts to quantify the importance of each feature for 
describing the variability of the data set. The basic concept used is that the measurement of the variance along each principle component will provide a means for comparing the relative importance of each feature. Measuring the magnitude of each vector component will identify important flight parameters in each of the component. The top 20 ranked parameters over all the components will be obtained on basis of their absolute magnitude. Although the main purpose of the PCA technique is to reduce dimensions in the data set, this paper exploits the potential of the PCA to determine which flight parameters are important or of significance during approach and landing phases. As per the knowledge of the authors, in the domain of aviation, this is first time that PCA has been used to determine the significant parameters as well as the ranking of the flight parameters was done over last three minutes of the flight time. Prior to the demonstration of the technique, the following section defines the level of pre-processing of the raw data that was required.

\section{A. Data pre-processing}

The data used for this study is from three specific aircraft (identified by the tail numbers), flown over given period of time. A fourth dataset includes a mixture of all tail numbers. The data set has 186 flight parameters sampled at different rates $(1 \mathrm{~Hz}$ to $16 \mathrm{~Hz})$. It is to be noted that the recorded data, as provided by NASA [17] has been disidentified to protect the identities of the airlines, as well as the flight crew involved during the actual flights. Data from MAT files were converted into SQL tables to better access the data. Sampling rate for the parameters ranges from $1 \mathrm{~Hz}$ to $16 \mathrm{~Hz}$. All parameters were converted to $16 \mathrm{~Hz}$ by interpolating the values for parameters sampled at the lower rates. Data was cleaned of any noise or miss readings in the parameters and synchronised such that all aircraft touch down on the same timeline. The Weight on Wheels (WOW) parameter was used to establish the aircraft's contact with the ground, thus synchronising all the aircraft landing on same runway with each other. Latitude (LAT) and longitude (LONG) parameters have been used to narrow down the runway used. All the flights for a given airport was adjusted for the minimum altitude to avoid negative values. The last three minutes of approach and landing phase were hence identified providing a total of 2880 data points for each flight parameter.

Out of total 186 flight parameters, 77 parameters which reflect pilot input and/or aircraft behaviour were selected for the analysis following discussions with industrial experts. All the environmental parameters were removed as the focus was on the parameters related with the pilot inputs and more importantly analysing parameters important for the stable approach. Any parameter related with the weather will be taken care by subsequent input by the pilot. Further, navigational parameters, parameters related to aircraft warning system and constant parameters such as engine number were removed from the analysis. The list of 77 parameters taken up for this study is given in Appendix 1.

An example of the data pre-processing for time versus altitude (ALT) for 600 flights arriving at the Detroit airport for one particular tail number 652 is shown in Fig. 2. Prior to PCA analysis, 77 parameters were reduced to 47 parameters by taking the mean of the same parameter recorded by the different sensors as summarised in Appendix II. We also implemented an anomaly detection technique for each airport so we may analyse only normal flights and any flight not fitting into the normal pattern be eliminated. The discussion on anomaly detection technique applied is beyond the scope of this paper. Having described the pre-processing of the raw flight data, the next section describes the methodology in performing PCA.

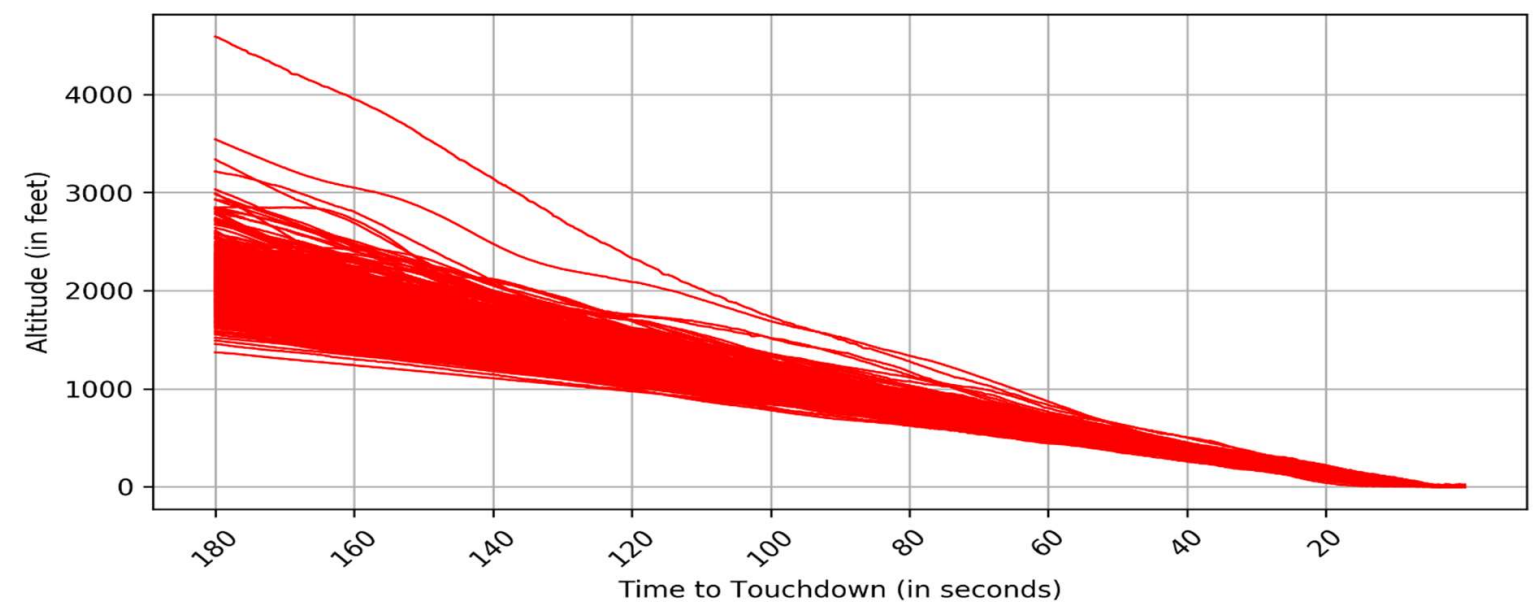

Fig. 2 Altitude against time to touchdown for Detroit airport (Tail 652, 600 flights) 


\section{B. Methodology}

Flight data is temporal in aspect. The analysis of this multivariate time series becomes challenging as it will have thousands of dimensions. For temporal patterns to be comparable, the time series data from all the flights are arranged in a way to form a matrix ' $M$ '. The major challenge in applying PCA over the given data set was how to stack sequential time series data in two-dimensional matrix. The dimension of this matrix is ' $m$ * $n$ ' where ' $m$ ' is the total number of flights and ' $n$ ' is the total number of features. Each flight has ' $p$ ' parameters and each of those parameters is recorded at ' $d$ ' time-steps, so there will be ' $p * d$ ' points in the feature space for the given flight. This ' $p * d$ ' forms the ' $n$ ' in the matrix $M$. Consider for each flight the feature space is defined as:

$$
\left[p_{1 d_{1}}, p_{2 d_{2}} \cdots p_{i d_{j}}\right]
$$

Where $p_{i d_{j}}$ is the value of the $i^{\text {th }}$ parameter from ' $p$ ' total parameters recorded at $j^{\text {th }}$ time-step and as there are ' $m$ ' total number of flights, so the matrix $M$ is given by

$$
M=m \cdot\left[p_{1 d_{1}}, p_{2 d_{2}} \cdots p_{i d_{j}}\right]
$$

All 47 parameters are evaluated over 2880 time-steps. For one flight, the analysis of one flight parameter over one time-step is one dimension. Likewise, for one flight with 47 parameters recorded at 2880 time-steps has 1,35,360 dimensions $\left(47^{*} 2880\right)$. The analysis for each airport in our study started with 600 flights for that particular aircraft (Tail number). This was however amended to remove the anomalous flights. The matrix $M$, input for the PCA algorithm is defined as:

$$
M=[(600-x)] \cdot[135360]
$$

Where ' $x$ ' is the number of anomalous flights. Thus, PCA was applied to reduce the number of dimensions. In our algorithm, we fixed the variance ratio as $95 \%$, thus, to capture $95 \%$ of the variance in the data set. This high percentage of variance ratio was taken to retain the maximum significant information using:

$$
\frac{\sum_{i=1}^{Z} V_{i}}{\sum_{i=1}^{F} V i}=95 \%
$$

Where ' $V i$ ' is the variance explained by the principal component and ' $F$ ' is the total number of principal components, which equals to ' $n$ ', the original number of dimensions $(1,35,360)$. ' $Z$ ' is the number of principal components kept. In our case, principal components varied as our main aim was to know the significant flight parameters during approach and landing phases. For each airport this retained $95 \%$ of the information

After performing the PCA, the number of dimensions were significantly reduced from 135360 to between 320 and 340 . The difference in number of principal components is due to the varying anomalies from one airport to another. It was demonstrated that the dimensions of the time series data can be significantly reduced while retaining $95 \%$ of the information. Though this has many advantages to allow other techniques to be applied at a lower computational effort and has indeed been applied in Ref. [18], the main purpose of this paper is to use PCA to learn the significant flight parameters during approach and landing phases. For this purpose, the principal components generated were further analysed.

The basic mathematics used to achieve this is to select parameters according to the magnitude (from smallest to largest in absolute values) of their coefficients in each of the principal component generated (we generated 320-340 components). There are two observations to be noted in this part.

1. We are interested in the magnitude of each parameter to get the contribution of that parameter in each of the component. We are ignoring the direction (positive or negative) and therefore, we took the absolute values.

2. Also, in our case the parameters with small coefficient values are of more significance as they were more stable or offered less variance. This can be interpreted as the attention was paid by the crew of the aircraft for a given airport to the parameters with less magnitude. These parameters become more significant for us.

The eigenvectors (principal components) determine the directions of the new feature space, and the eigenvalues determine their magnitude. In other words, the eigenvalues explain the variance of the data along the new feature axes. Though, the detailed mathematical discussion on the working of PCA algorithm is beyond the scope of this paper but to summarise the last step it can be concluded that the importance of each feature is reflected by the absolute values (magnitude) of the eigenvectors' components corresponding to the ' $F$ ' (from "Eq. (4)") largest eigenvalues. Further to achieve our objective we calculated the frequency i.e. the number of times a parameter occurred as top 20 in each of the principal component generated (320-340 components). For a given case, we are having 320 principal components, and, in each component, we calculated top 20 parameters (least variant parameters) by arranging parameters in order of their 
magnitude as explained above. In the same manner, we calculate top 20 parameters for 320 components and rank them in decreasing order of their frequency count to see the most significant parameters.

The technique described above was repeated for the entire time frame of three minutes to reflect the whole approach phase as well as on a moving 30 seconds time frame along the approach phase. The latter highlights the dynamic nature of approach and landing phases and allows to establish how the importance of the parameters change in time as the aircraft nears touchdown. To simplify the results, the flight parameters are grouped into 5 categories as listed in Table 2. Each category represents the mean value of the frequency count of the flight parameters included in that category.

Table 2 Categories of flight parameters

\begin{tabular}{|l|l|}
\hline \multicolumn{1}{|c|}{ Category } & \multicolumn{1}{c|}{ Flight Parameters } \\
\hline Altitude & ALT, RALT, BAL \\
\hline Speed & MACH, TAS, GS \& CAS \\
\hline Engine Systems & N1, N2 \& FF \\
\hline Aircraft State & PTCH, IVV, AOAC, AOAI, ROLL, ALTR, \& LGDN \\
\hline Flight Control System & FLAP, RUDD, SPL, ABRK \& GLS \\
\hline
\end{tabular}

\section{Results and Discussion}

The following results demonstrate the significance of the flight parameters in the last three minutes. It can be shown that while the current stable approach criteria provide guidelines that are easier to follow, implement and assess, a deeper analysis at the data demonstrates that each airport has its own particularities which are then reflected in pilot response and aircraft parameters. Fig. 3(a) and Fig. 3(b) shows a plot of the flights for aircraft tail number 652, 653 and 654 as they approach five different airports in the US. While for some airports (such as CVG and OKC) all tail number flight parameters show a very similar trends, the flights approaching DTW, MEM and MSP contain subtle variations among the flight categories across different tail numbers. This, notwithstanding the fact that the aircraft type and airport is the same. While a human may give equal importance to all the stabilization criteria, the data shows that this is not always the case and subtle variations across various airports exist.
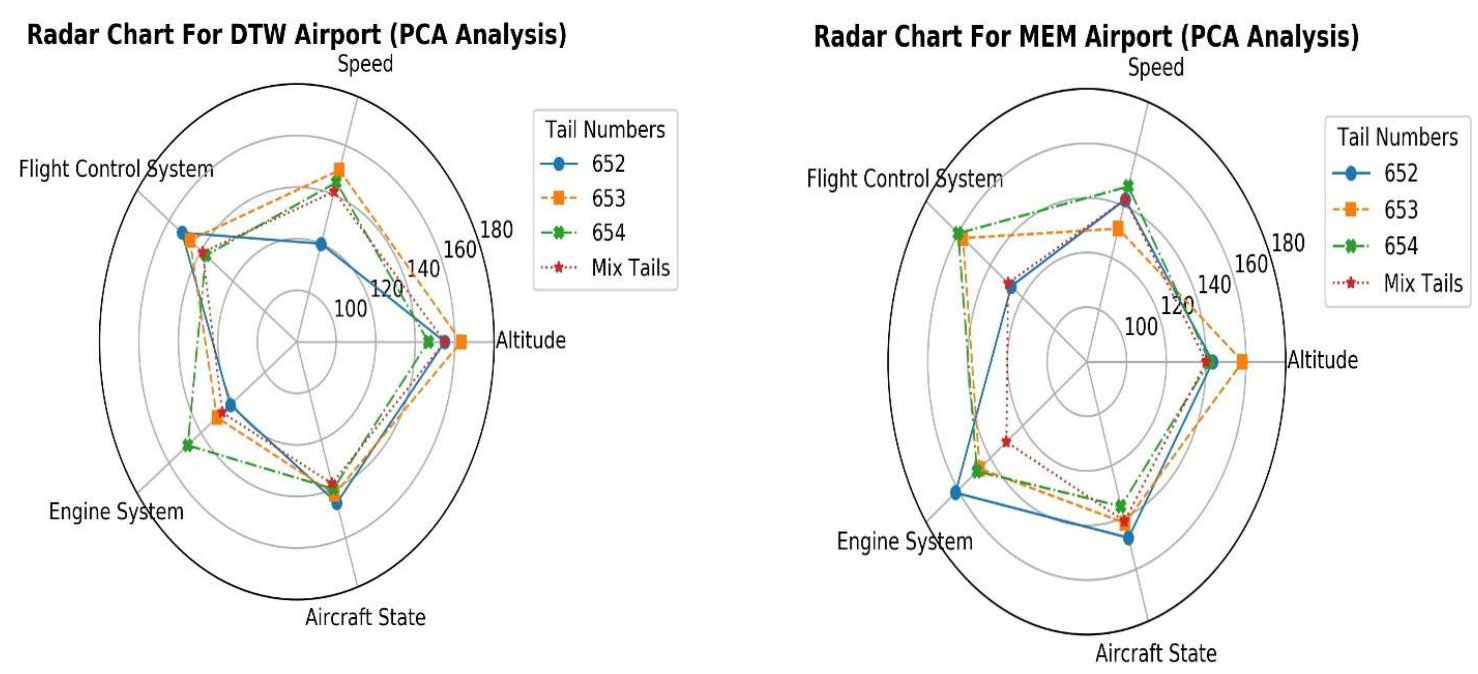

Fig. 3 (a) Comparison of flight categories across various airports and tail numbers. 

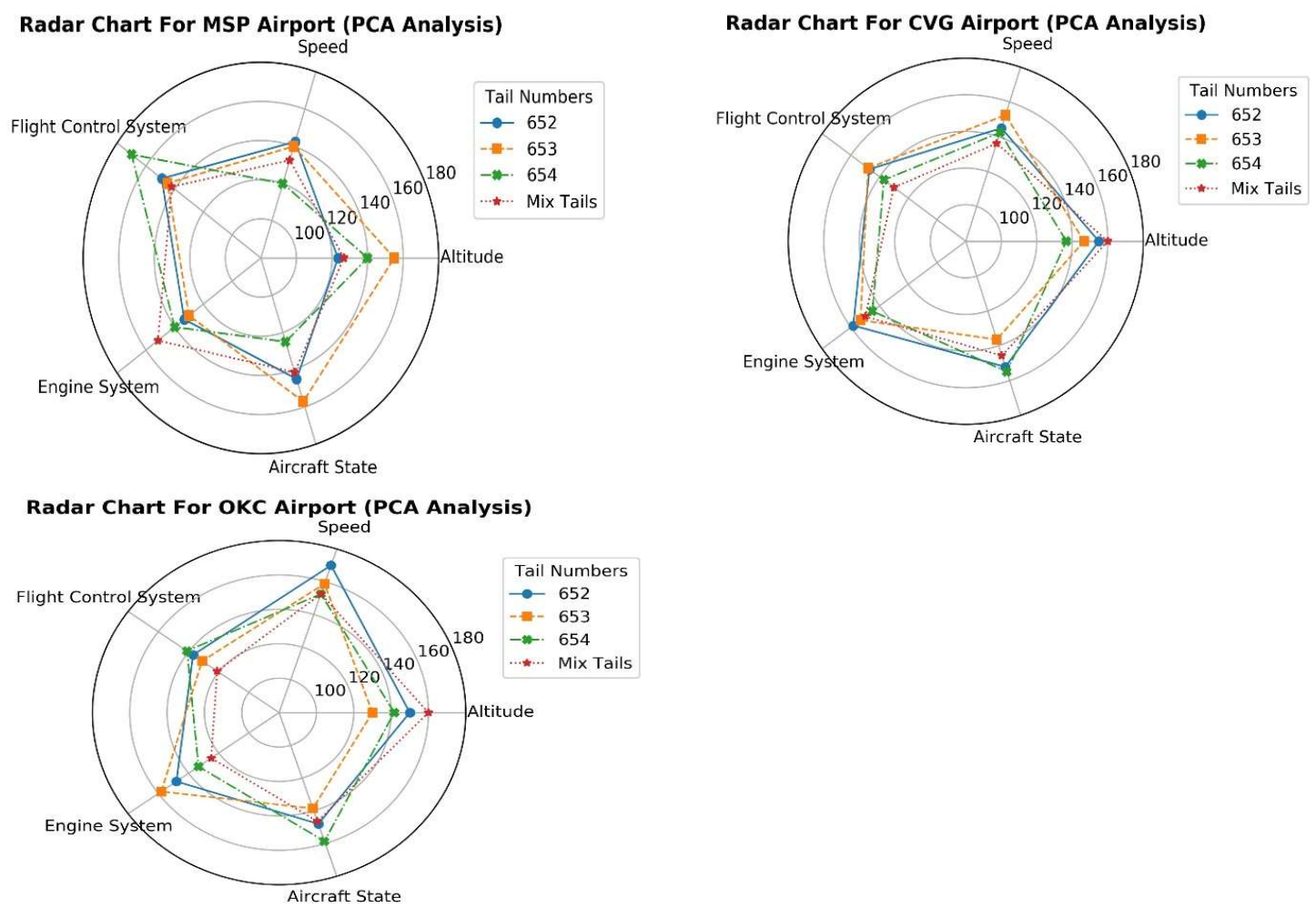

Fig. 3 (b) Comparison of flight categories across various airports and tail numbers.

This paper considers a case study for aircraft landing in Detroit airport (DTW) for a more in-depth analysis of the parameters making up the categories themselves in Fig. 4. To ease interpretation, the variance of the flight parameters across all flights of aircraft tail numbers 652, 653, 654 is computed and shown in Fig. 5. It can be shown that parameters making up the Speed category, (which has a large deviation between aircraft tail number 652 and tail numbers 653, 654), experiences large standard deviation in $\mathrm{MACH}$ and CAS, while lower variation in TAS and GS. One might argue that the latter parameters increase in importance as the aircraft approaches touch down and should be the only ones considered in the speed category. It is however interesting to note why the pattern is not repeatable across all airports. A similar trend is present for the Engine System category for aircraft tail number 654, with the flight parameter N1 experiencing a high standard deviation.

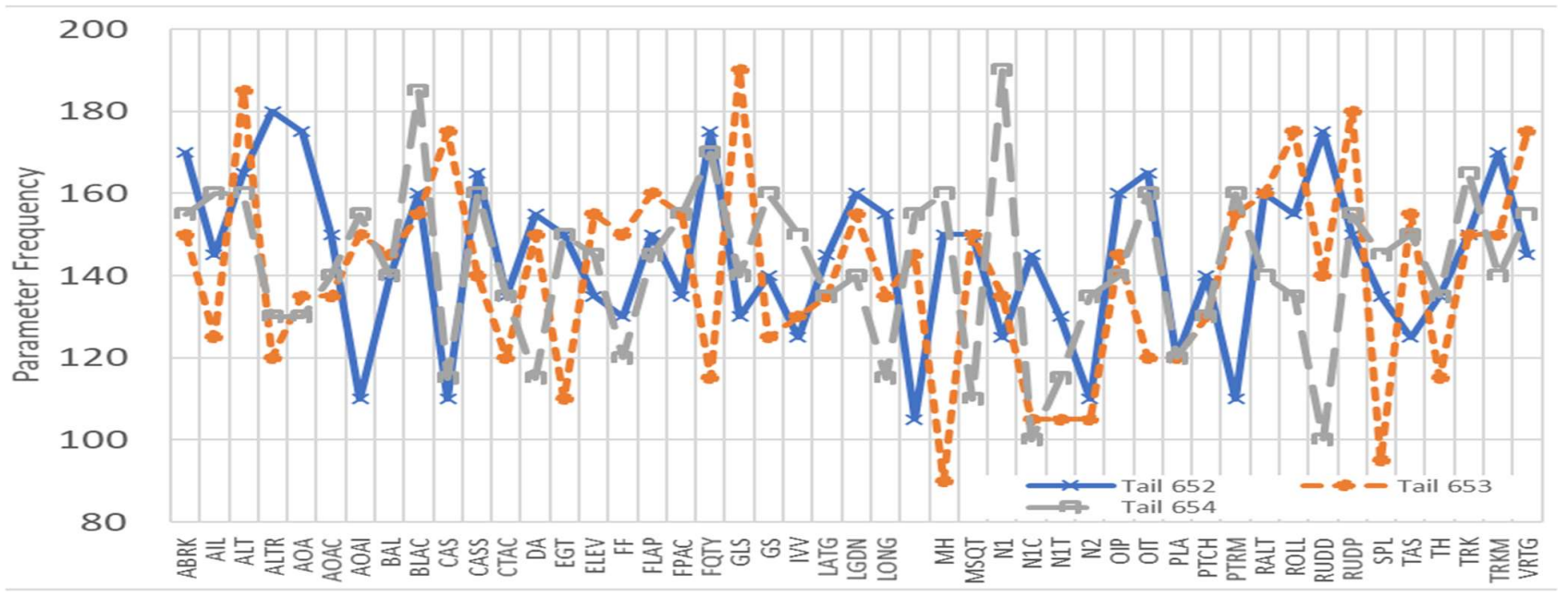

Fig. 4 Frequency of all the flight Parameters across 3 tails for Detroit airport (1800 flights) 


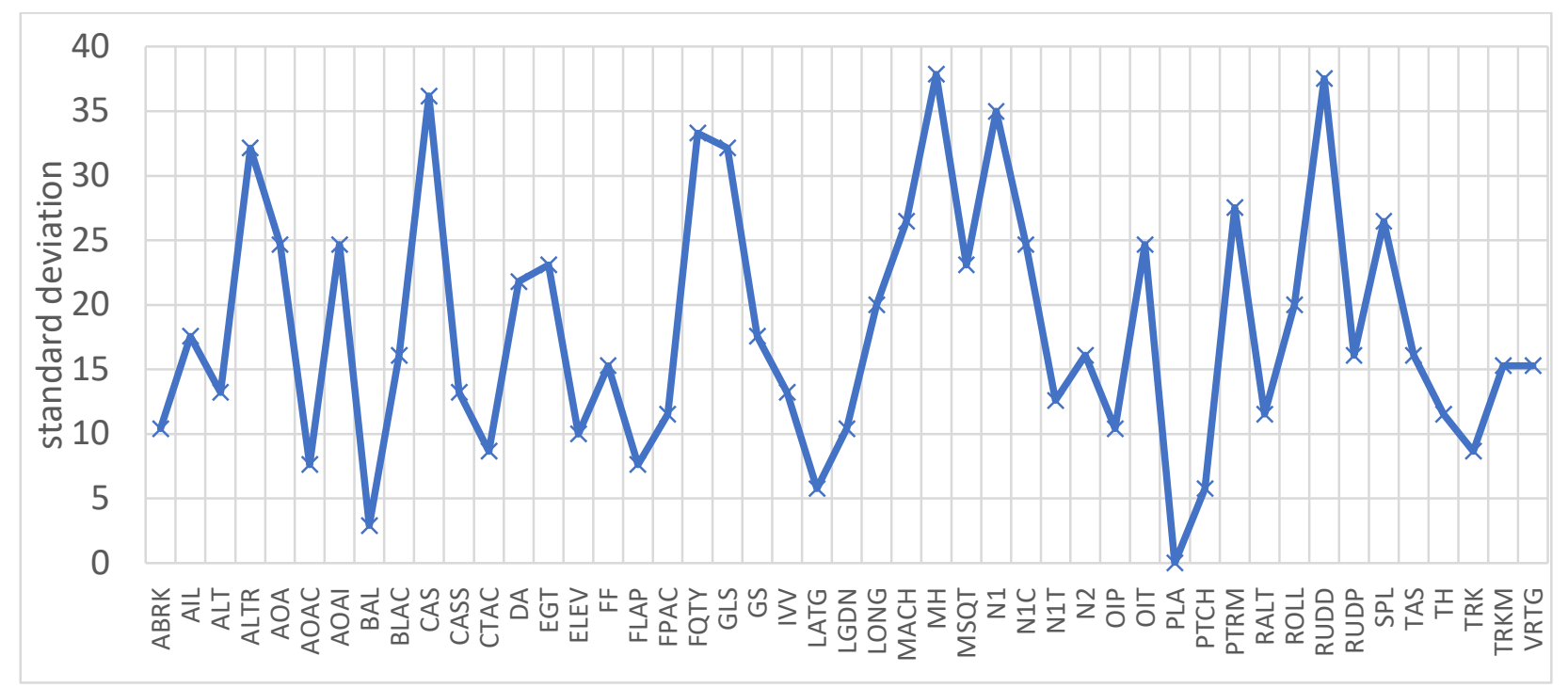

Fig. 5 Standard deviation of all the flight parameters across 3 tails for Detroit airport (1800 flights)

The dynamic nature of the flight parameters was also studied with the aim to capture how the importance of flight parameters changes as the aircraft travels through the three-minute time frame and approaches touchdown. Fig. 6 shows this for a case study for the aircraft approaching DTW airport. It can be shown that as the aircraft is furthest away from touchdown, priority is given to achieve the aircraft in its correct state. As the aircraft approaches further priority is given to maintain altitude and flight control system parameters. At a point where the aircraft is within 30 s from touchdown, aircraft speed becomes of utmost importance. The variation of the actual parameters in time is further explained in Fig. 7.

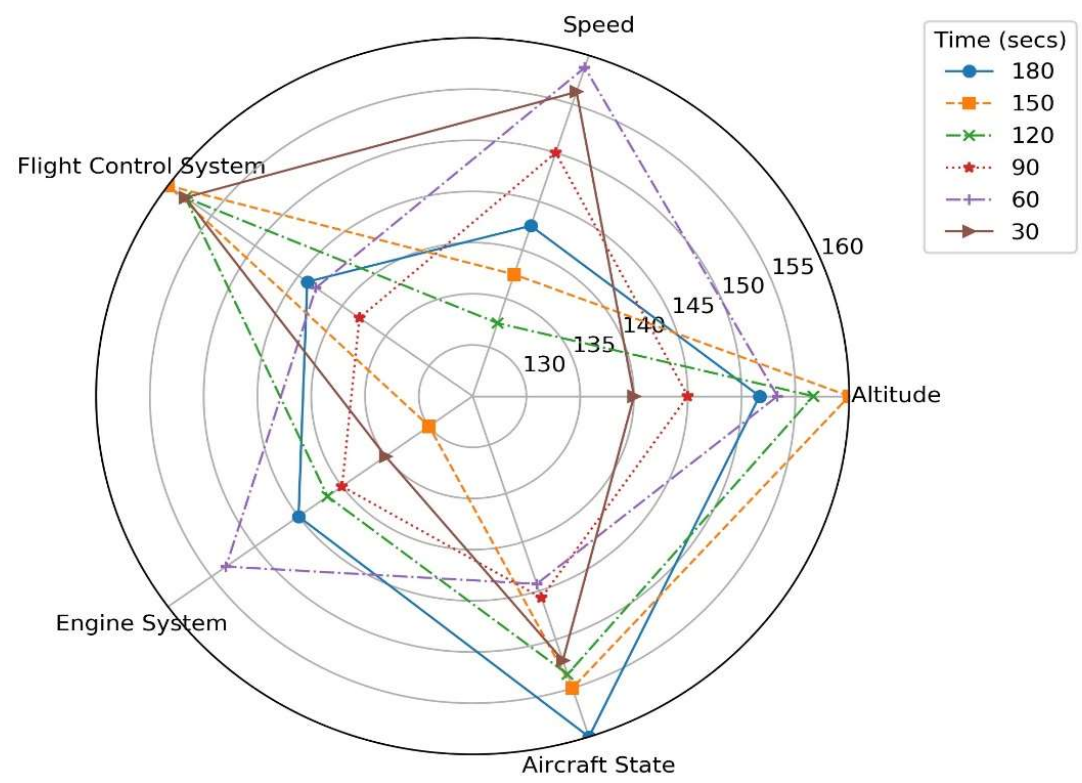

Fig. 6 Significance of flight categories over the time for Detroit airport (Tail 652, 1800 flights). 

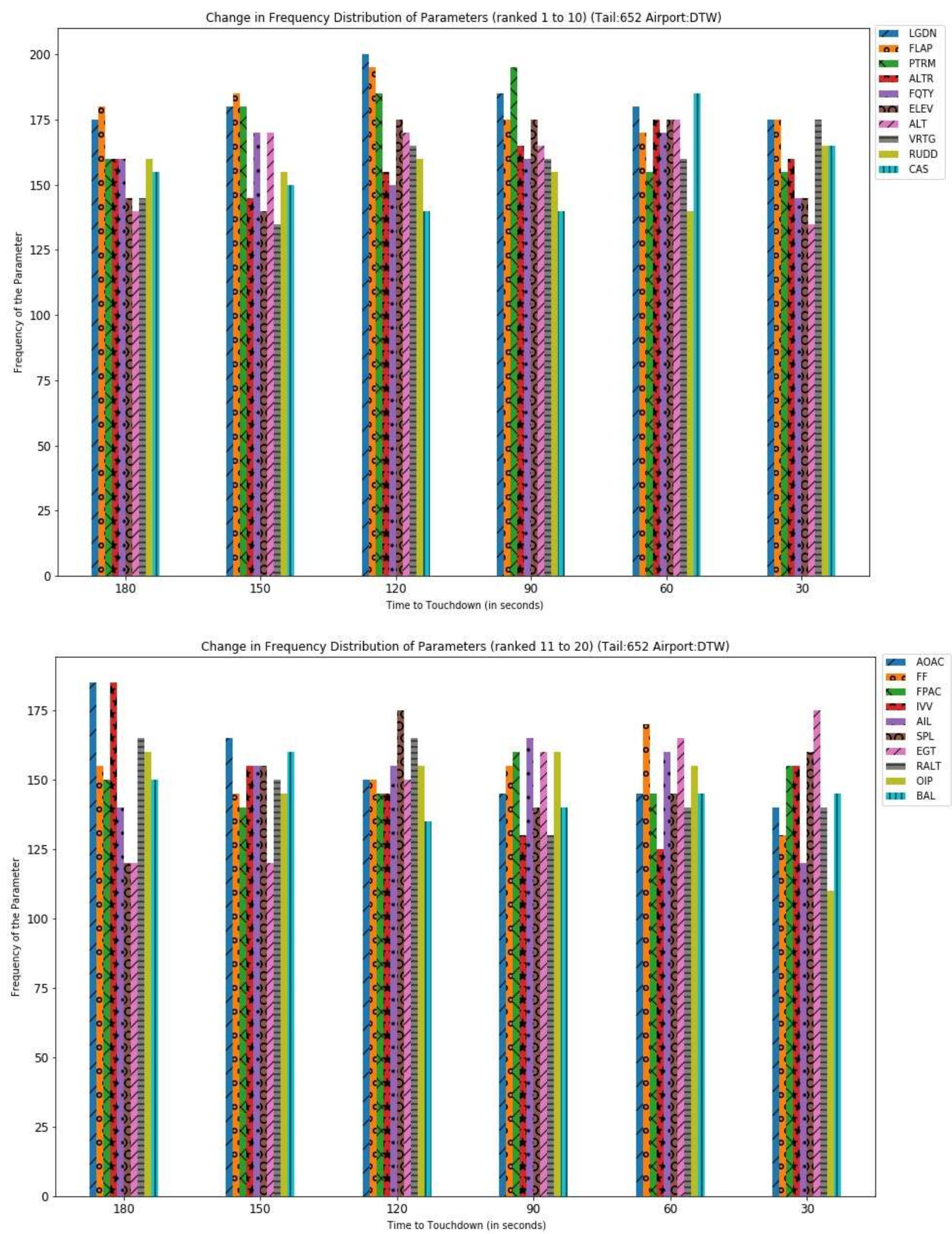

Fig. 7 Change in top 20 parameters over the time for Detroit airport (Tail 652, 1800 flights). 


\section{Conclusion and Future work}

This paper presented the use of Principle Component Analysis as a technique to re-evaluate the stabilization criteria during approach and landing phases of an aircraft. It can be demonstrated that while the stabilization criteria defined by industry experts and built over experience is corroborated with data. However, while such general criteria can be easy to implement and assess, the data itself suggest that subtle differences between aircraft and airports may exist. The importance of certain flight parameters appears to change, varying on airport location. The authors theorize that this is likely due to the airport geographic location itself, and the susceptibility to bad weather. This however requires further investigation.

Principle Component Analysis was used to establish the variations of flight parameters between various flights from three aircraft tail numbers and five airports. The technique was also used to investigate the importance of the flight parameters as the aircraft approaches closer to touchdown. It is interesting to note how the importance of specific flight parameters shifts along the entire three-minute time window considered for the approach phase. In future the authors seek to present a cross comparison of PCA with different machine learning techniques.

\section{Appendix I: Definition of aircraft flight parameters}

\begin{tabular}{|c|c|c|}
\hline S.No. & Parameter Name & Description \\
\hline 1. & ABRK & Air BRaKe Position in Degrees. \\
\hline 2. & AIL_1 & $\begin{array}{l}\text { AILeron Number } 1 \text { deflection angle in Degrees. Left (Port) Wing } \\
\text { aileron surface. }\end{array}$ \\
\hline 3. & AIL_2 & $\begin{array}{l}\text { AILeron Number } 2 \text { deflection angle in Degrees. Right (Starboard) } \\
\text { Wing aileron surface }\end{array}$ \\
\hline 4. & ALT & $\begin{array}{l}\text { Pressure ALTitude measured in Feet. Aircraft flight altitude calibrated } \\
\text { as per the pressure setting on the altimeter. }\end{array}$ \\
\hline 5. & ALTR & $\begin{array}{l}\text { ALTitude Rate measured in Feet/Minute. The rate of change in altitude. } \\
\text { This indicates at what rate the aircraft is climbing or descending. }\end{array}$ \\
\hline 6. & AOA1 & $\begin{array}{l}\text { Angle of Attack sensor number 1. The angle of attack is the angle } \\
\text { between the aircraft longitudinal axis and the aircraft flight path. }\end{array}$ \\
\hline 7. & AOA2 & $\begin{array}{l}\text { Angle of Attack sensor number 2. The angle of attack is the angle } \\
\text { between the aircraft longitudinal axis and the aircraft flight path. }\end{array}$ \\
\hline 8. & $\mathrm{AOAC}$ & Corrected Angle of Attack measured in Degrees. \\
\hline 9. & AOAI & $\begin{array}{l}\text { Indicated Angle of Attack measured in Degrees. This is the angle of } \\
\text { attack indicated to the pilot after correcting for errors between AOA1 } \\
\text { and AOA2. }\end{array}$ \\
\hline 10. & BAL1 & $\begin{array}{l}\text { Barometrically Corrected ALtitude 1. Altitude indicated to the pilot } \\
\text { seated on the left based on QNH or QNE (some Airlines may also opt } \\
\text { to use QFE) }\end{array}$ \\
\hline 11. & BAL2 & $\begin{array}{l}\text { Barometrically Corrected ALtitude 2. Altitude indicated to the pilot } \\
\text { seated on the right based on QNH or QNE (some Airlines may also opt } \\
\text { to use QFE) }\end{array}$ \\
\hline 12. & BLAC & Body Longitudinal ACceleration measured in $\mathrm{g}$ \\
\hline 13. & CAS & $\begin{array}{l}\text { Computed AirSpeed measured in Knots. The airspeed indicated to the } \\
\text { pilots on their airspeed indicator instruments }\end{array}$ \\
\hline 14. & CASS & $\begin{array}{l}\text { Selected Computed AirSpeed. Pilot selected speed, when flying with } \\
\text { speed in CAS, for the Auto Pilot }\end{array}$ \\
\hline 15. & CTAC & Cross Track ACceleration measured in $\mathrm{g}$ \\
\hline 16. & DA & $\begin{array}{l}\text { Drift Angle measured in Degrees (DEG). This is equal to the Wind } \\
\text { Correction Angle. It is the difference between the Magnetic/True } \\
\text { Heading (MH/TH) and the Magnetic/True Track (TRKM/TRK). To fly } \\
\text { the required track the aircraft corrects for wind drift by applying the } \\
\text { Drift Angle to the Heading. This results in the heading to be flown to } \\
\text { maintain the required track. }\end{array}$ \\
\hline 17. & EGT_1 & $\begin{array}{l}\text { Engine Number } 1 \text { Exhaust Gas Temperature. Very high EGT may } \\
\text { indicate a problem. }\end{array}$ \\
\hline
\end{tabular}




\begin{tabular}{|c|c|c|}
\hline 18. & EGT_2 & $\begin{array}{l}\text { Engine Number } 2 \text { Exhaust Gas Temperature. Very high EGT may } \\
\text { indicate a problem. }\end{array}$ \\
\hline 19. & EGT_3 & $\begin{array}{l}\text { Engine Number } 3 \text { Exhaust Gas Temperature. Very high EGT may } \\
\text { indicate a problem. }\end{array}$ \\
\hline 20. & EGT_4 & $\begin{array}{l}\text { Engine Number } 4 \text { Exhaust Gas Temperature. Very high EGT may } \\
\text { indicate a problem. }\end{array}$ \\
\hline 21. & ELEV_1 & $\begin{array}{l}\text { ELEVator Number } 1 \text { deflection angle in Degrees. Left (Port) Tailplane } \\
\text { elevator surface. }\end{array}$ \\
\hline 22. & ELEV_2 & $\begin{array}{l}\text { ELEVator Number } 2 \text { deflection angle in Degrees. Right (Starboard) } \\
\text { Tailplane elevator surface. }\end{array}$ \\
\hline 23. & FF 1 & Engine Number 1 Fuel Flow in Pounds per Hour (LBS/HR). \\
\hline 24. & FF 2 & Engine Number 2 Fuel Flow in Pounds per Hour (LBS/HR). \\
\hline 25. & FF 3 & Engine Number 3 Fuel Flow in Pounds per Hour (LBS/HR). \\
\hline 26. & FF_4 & Engine Number 4 Fuel Flow in Pounds per Hour (LBS/HR). \\
\hline 27. & FLAP & $\begin{array}{l}\text { Trailing Edge FLAP Position measured in counts. The BAE146/AVRO } \\
\text { RJ Series has five flap positions } 0^{\circ}, 18^{\circ}, 24^{\circ}, 30^{\circ} \text { and } 33^{\circ} \text { degrees. }\end{array}$ \\
\hline 28. & FPAC & $\begin{array}{l}\text { Flight Path ACceleration measured in g. This is the acceleration } \\
\text { measured along the aircraft's flight path. Similar to BLAC but not } \\
\text { projected out of the longitudinal axis of the aircraft but out of the actual } \\
\text { aircraft flight path. }\end{array}$ \\
\hline 29. & FQTY_1 & Fuel QuantiTY TANK 1 Left (Port) wing measured in Pounds (LBS). \\
\hline 30. & FQTY_2 & $\begin{array}{l}\text { Fuel QuantiTY TANK } 2 \text { Right (Starboard) wing measured in Pounds } \\
\text { (LBS). }\end{array}$ \\
\hline 31. & FQTY_3 & $\begin{array}{l}\text { Fuel QuantiTY TANK } 3 \text { Centre Pannier Tanks (if installed) measured } \\
\text { in Pounds (LBS). }\end{array}$ \\
\hline 32. & FQTY_4 & $\begin{array}{l}\text { Fuel QuantiTY TANK } 4 \text { Centre Pannier Tanks (if installed) measured } \\
\text { in Pounds (LBS). }\end{array}$ \\
\hline 33. & GLS & $\begin{array}{l}\text { GLide Slope Deviation. It indicates the aircraft's vertical path relative } \\
\text { to an ILS Glideslope. }\end{array}$ \\
\hline 34. & GS & $\begin{array}{l}\text { Ground Speed in Knots. This is the actual speed of the aircraft over the } \\
\text { Earth's surface after considering all external factors. }\end{array}$ \\
\hline 35. & IVV & $\begin{array}{l}\text { Inertial Vertical (Velocity) Speed in Feet/Minute. Similar to ALTR } \\
\text { however the measurement is being performed by the Inertial Reference } \\
\text { System (IRS) (Also known as INS - Inertial Navigation System). }\end{array}$ \\
\hline 36. & LATG & $\begin{array}{l}\text { LATeral acceleration measured in g. The lateral axis is an imaginary } \\
\text { line passing through the centre of the aircraft from port (left) to } \\
\text { starboard (right) (normally from wing tip to wing tip). Accelerations } \\
\text { about this axis affect the longitudinal stability (Pitch) of the aircraft. } \\
\text { Pitch is controlled by the Elevators however as for LONG above } \\
\text { external forces may also induce pitch }\end{array}$ \\
\hline 37. & LGDN & Landing Gear DowN Locked. \\
\hline 38. & LONG & $\begin{array}{l}\text { LONGitudinal acceleration measured in g. The longitudinal axis is an } \\
\text { imaginary line passing from the nose to the tail of the aircraft. } \\
\text { Accelerations about this axis affect the lateral stability (Roll) of the } \\
\text { aircraft. Roll is controlled by the Ailerons however roll may also be } \\
\text { induced by external forces. }\end{array}$ \\
\hline 39. & MACH & $\begin{array}{l}\text { MACH Number measured as a ratio of the Speed of Sound the measure } \\
\text { is simply referred to as Mach. The airspeed in Mach Number as } \\
\text { indicated to the pilots on their airspeed indicator instruments. }\end{array}$ \\
\hline 40. & MH & $\begin{array}{l}\text { Magnetic Heading measured in Degrees (DEG). This is where the } \\
\text { aircraft's nose is pointing relative to Magnetic North. }\end{array}$ \\
\hline 41. & MSQT_1 & $\begin{array}{l}\text { SQuaT switch left (1) Main gear. It indicates if aircraft weight is on the } \\
\text { left main gear wheel. Used to indicate how the aircraft took off or } \\
\text { landed. }\end{array}$ \\
\hline
\end{tabular}




\begin{tabular}{|c|c|c|}
\hline 42. & MSQT_2 & $\begin{array}{l}\text { SQuaT switch right (2) Main gear. It indicates if aircraft weight is on } \\
\text { the right main gear wheel. Used to indicate how the aircraft took off or } \\
\text { landed. }\end{array}$ \\
\hline 43. & N1_1 & $\begin{array}{l}\text { Engine Number } 1 \text { Fan (N1) speed in \% RPM. Very low or } 0 \% \text { RPM } \\
\text { during flight indicates a seized engine. }\end{array}$ \\
\hline 44. & N1_2 & $\begin{array}{l}\text { Engine Number } 2 \text { Fan (N1) speed in \% RPM. Very low or } 0 \% \text { RPM } \\
\text { during flight indicates a seized engine. }\end{array}$ \\
\hline 45. & N1_3 & $\begin{array}{l}\text { Engine Number } 3 \text { Fan (N1) speed in \% RPM. Very low or } 0 \% \text { RPM } \\
\text { during flight indicates a seized engine. }\end{array}$ \\
\hline 46. & N1_4 & $\begin{array}{l}\text { Engine Number } 4 \text { Fan (N1) speed in \% RPM. Very low or } 0 \% \text { RPM } \\
\text { during flight indicates a seized engine. }\end{array}$ \\
\hline 47. & $\mathrm{~N} 1 \mathrm{C}$ & $\begin{array}{l}\text { N1 Command. Autothrottle commands an N1 RPM for all engines } \\
\text { based on the autothrottle mode to maintain the required thrust. }\end{array}$ \\
\hline 48. & N1T & $\begin{array}{l}\text { Selected Engine N1 Target RPM. Pilot selected engine N1 Target } \\
\text { (applies to all engines) to be maintained by the autothrottle system. }\end{array}$ \\
\hline 49. & N2_1 & $\begin{array}{l}\text { Engine Number } 1 \text { Core (N2) speed in \% RPM. Very low or } 0 \% \text { RPM } \\
\text { during flight indicates a seized engine. }\end{array}$ \\
\hline 50. & N2_2 & $\begin{array}{l}\text { Engine Number } 2 \text { Core (N2) speed in \% RPM. Very low or } 0 \% \text { RPM } \\
\text { during flight indicates a seized engine. }\end{array}$ \\
\hline 51. & N2_3 & $\begin{array}{l}\text { Engine Number } 3 \text { Core (N2) speed in \% RPM. Very low or } 0 \% \text { RPM } \\
\text { during flight indicates a seized engine. }\end{array}$ \\
\hline 52. & N2_4 & $\begin{array}{l}\text { Engine Number } 4 \text { Core (N2) speed in \% RPM. Very low or } 0 \% \text { RPM } \\
\text { during flight indicates a seized engine. }\end{array}$ \\
\hline 53. & OIP_1 & $\begin{array}{l}\text { Engine Number } 1 \text { OIl Pressure. Measured in Pounds per Square Inch } \\
\text { (PSI). Low oil pressure or excessively high oil pressure during flight } \\
\text { may indicate an engine problem. }\end{array}$ \\
\hline 54. & OIP_2 & $\begin{array}{l}\text { Engine Number } 2 \text { OIl Pressure. Measured in Pounds per Square Inch } \\
\text { (PSI). Low oil pressure or excessively high oil pressure during flight } \\
\text { may indicate an engine problem. }\end{array}$ \\
\hline 55. & OIP_3 & $\begin{array}{l}\text { Engine Number } 3 \text { OIl Pressure. Measured in Pounds per Square Inch } \\
\text { (PSI). Low oil pressure or excessively high oil pressure during flight } \\
\text { may indicate an engine problem. }\end{array}$ \\
\hline 56. & OIP_4 & $\begin{array}{l}\text { Engine Number } 4 \text { OIl Pressure. Measured in Pounds per Square Inch } \\
\text { (PSI). Low oil pressure or excessively high oil pressure during flight } \\
\text { may indicate an engine problem. }\end{array}$ \\
\hline 57. & OIT_1 & $\begin{array}{l}\text { Engine Number } 1 \text { OIl Temperature. Measured in Degrees (DEG) } \\
\text { Celsius. }\end{array}$ \\
\hline 58. & OIT_2 & $\begin{array}{l}\text { Engine Number } 2 \text { OIl Temperature. Measured in Degrees (DEG) } \\
\text { Celsius. }\end{array}$ \\
\hline 59. & OIT_3 & $\begin{array}{l}\text { Engine Number } 3 \text { OIl Temperature. Measured in Degrees (DEG) } \\
\text { Celsius. }\end{array}$ \\
\hline 60. & OIT_4 & $\begin{array}{l}\text { Engine Number } 4 \text { OIl Temperature. Measured in Degrees (DEG) } \\
\text { Celsius. }\end{array}$ \\
\hline 61. & PLA 1 & Power Lever Angle for engine number 1 \\
\hline 62. & PLA_2 & Power Lever Angle for engine number $\mathbf{2}$ \\
\hline 63. & PLA_3 & Power Lever Angle for engine number 3 \\
\hline 64. & PLA_ 4 & Power Lever Angle for engine number 4 \\
\hline 65. & PTCH & $\begin{array}{l}\text { PiTCH angle measured in Degrees. The Angle between the Horizon } \\
\text { and the aircraft longitudinal axis. }\end{array}$ \\
\hline 66. & PTRM & Pitch TRiM Position. Measured in Degrees. \\
\hline 67. & RALT & $\begin{array}{l}\text { Radio ALTitude measured in Feet. This is a very sensitive instrument } \\
\text { which is activated when in close proximity to the Earth's surface, } \\
\text { typically within } 5000 \text { Feet. This instrument gives very accurate height } \\
\text { above terrain information during Take-Off and Landing. }\end{array}$ \\
\hline 68. & ROLL & $\begin{array}{l}\text { Aircraft ROLL Angle in Degrees. The roll angle caused by the } \\
\text { displacement of the ailerons and/or external environmental factors. }\end{array}$ \\
\hline
\end{tabular}




\begin{tabular}{|r|l|l|}
\hline 69. & RUDD & $\begin{array}{l}\text { RUDDer deflection angle in Degrees. 0 degrees is the centre position } \\
\text { and -ve and +ve values determine the deflection left or right. }\end{array}$ \\
\hline 70. & RUDP & RUDder Pedal Position. Indicates yaw inputs measured in counts. \\
\hline 72. & SPL_1 & $\begin{array}{l}\text { Roll SPoiLer 1 deflection angle in Degrees. Left (Port) Wing spoiler } \\
\text { surface. }\end{array}$ \\
\hline 73. & TAS & $\begin{array}{l}\text { Roll SPoiLer 1 deflection angle in Degrees. Right (Starboard) Wing } \\
\text { spoiler surface. }\end{array}$ \\
\hline 74. & TH & $\begin{array}{l}\text { True AirSpeed measured in Knots. Actual aircraft speed through the } \\
\text { air. }\end{array}$ \\
\hline 75. & TRK & $\begin{array}{l}\text { True Heading measured in Degrees (DEG). This is where the aircraft's } \\
\text { nose is pointing relative to True North. }\end{array}$ \\
\hline 76. & TRKM & $\begin{array}{l}\text { TRacK Angle True measured in Degrees (DEG). This is the aircraft's } \\
\text { track over the Earth's surface relative to True North. }\end{array}$ \\
\hline 77. & VRTG & $\begin{array}{l}\text { TRacK Angle Magnetic measured in Degrees (DEG). This is the } \\
\text { aircraft's track over the Earth's surface relative to Magnetic North. }\end{array}$ \\
\hline
\end{tabular}

\section{Appendix II: Reduced parameters}

\begin{tabular}{|l|l|}
\hline Parameter & Mean of Parameters \\
\hline N1 & N1_1, N1_2, N1_3 and N1_4 \\
\hline N2 & N2_1, N2_2, N3_3 and N4_4 \\
\hline FQTY & FQTY_1, FQTY_2, FQTY_3 and FQTY_4 \\
\hline OIT & OIT_1, OIT_2, OIT_3 and OIT_4 \\
\hline EGT & EGT_1, EGT_2, EGT_3 and EGT_4 \\
\hline FF & FF_1, FF_2, FF_3 and FF_4 \\
\hline PLA & PLA_1, PLA_2, PLA_3 and PLA_4 \\
\hline OIP & OIP_1, OIP_2, OIP_3 and OIP_4 \\
\hline AIL & AIL_1 and AIL_2 \\
\hline SPL & SPL_1 and SPL_2 \\
\hline BAL & BAL_1 and BAL_2 \\
\hline AOA & AOA_1 and AOA_2 \\
\hline MSQT & MSQT_1 and MSQT_2 \\
\hline ELEV & ELEV_1 and ELEV_2 \\
\hline
\end{tabular}

\section{Acknowledgement}

This research is a result of Project Smart FDM financed by the Malta Council for Science \& Technology, for and on behalf of the Foundation for Science and Technology, through the FUSION: R\&I Technology Development Programme. 


\section{References}

[1] Fernandes, R. "An analysis of the potential benefits to airlines of flight data monitoring programs," MSc. Thesis, School of Engineering Air Transport Group, Cranfield University, Cranfield, Bedford MK43 0AL, UK, 2002.

[2] The Bureau of Enquiry and Analysis for Civil Aviation report Accident Investigation Report Gulf Air Flight GF-072 https://www.bea.aero/docspa/2000/a40-ek000823a/htm/a40-ek000823a.html[retrieved 3 June 2019].

[3] BOEING, 1959-2001, Statistical Summary of Commercial Jet Airplane Accidents (2018). http://www.boeing.com/resources/boeingdotcom/company/about_bca/pdf/statsum.pdf [retrieved 5 June 2019].

[4] Flight Safety Foundation ALAR Briefing Note 4.2 - Energy Management," 2000.

[5] unstable-approaches-2016-2nd-edition.pdf, IATA, 2016.

[6] Jianqing, F. Fang, H. Han, L., "Challenges of Big Data analysis", National Science Review, Vol. 1, Issue 2, June 2014, Pages 293-314. DOI: $10.1093 / \mathrm{nsr} / \mathrm{nwt} 032$

[7] Federal Aviation Administration, 14 CFR 121.344 Digital Flight Data Recorders for Transport Category Airplanes, 2011

[8] Li, L., Das, S., John Hansman, R., Palacios, R., \& Srivastava, A. (2015). Analysis of Flight Data Using Clustering Techniques for Detecting Abnormal Operations. Journal of Aerospace Information Systems, 12(9), 587-598. http://dx.doi.org/10.2514/1.i010329

[9] Li, L., Hansman, R., Palacios, R., \& Welsch, R. (2016). Anomaly detection via a Gaussian Mixture Model for flight operation \& safety monitoring. Transportation Research Part C: Emerging Technologies, 64, 45-5 http://dx.doi.org/10.1016/j.trc.2016.01.007

[10] Jasra, S., Gauci, J., Muscat, A., Valentino, G., Zammit-Mangion, D. \& and Camilleri, R., "Literature Review of Machine Learning Techniques to Analyse Flight Data", AEGATS Conference, Toulouse, France 23-25, October 2018

[11] Bellman, R. E. Adaptive Control Processes: A Guided Tour (Princeton Univ. Press, Princeton, NJ, 1961)

[12] Theodoridis, S., Koutroumbas, K., "Pattern recognition and neural networks.” In: Paliouras, G., Karkaletsis, V., Spyropoulos CD (eds), "Machine learning and its applications.", Berlin: Springer, 2001, pp.169-195

[13] Jain, A., Zongker, D., "Feature selection: evaluation, application, and small sample performance.” IEEE Transactions on Pattern Analysis and Machine Intelligence, 1997, 19(2), 153-158. doi: 10.1109/34.574797 5201

[14] Pearson, K., "On Lines and Planes of Closest Fit to Systems of Points in Space," Philosophical Magazine Series 6, vol. 2 Nov. 1901, pp. 559-572.

[15] Hotelling, H., "Analysis of a Complex of Statistical Variables into Principal Components.," Journal of Educationa Psychology, vol. 24, 1933, pp. 417-441, pp. 498-520.

[16] Shlens, J., "A Tutorial on Principal Component Analysis - arXiv" Available: https://arxiv.org/pdf/1404.1100.pdf.

[17] "DASHlink - Sample Flight Data," NASA Available: https:/c3.nasa.gov/dashlink/projects/85/.

[18] Li, L., Gariel, M., Hansman, R. J., and Palacios, R., "Anomaly detection in onboard-recorded flight data using cluster analysis,” 2011 IEEE/AIAA 30th Digit. Avion. Syst. Conf., p. 4A4-1-4A4-11, 2011 